\title{
Article
}

\section{Identifying Challenging Job and Environmental Demands of Older Nurses Within the National Health Service}

Durosaiye, Isaiah Oluremi, Hadjri, Karim and Liyanage, Champika Lasanthi

Available at http://clok.uclan.ac.uk/12668/

Durosaiye, Isaiah Oluremi ORCID: 0000-0001-7290-7443, Hadjri, Karim ORCID: 0000-0001-8243-8396 and Liyanage, Champika Lasanthi ORCID: 0000-00016687-3611 (2016) Identifying Challenging Job and Environmental Demands of Older Nurses Within the National Health Service. HERD, 9 (3). pp. 82-105. ISSN 1937-5867

It is advisable to refer to the publisher's version if you intend to cite from the work. http://dx.doi.org/10.1177/1937586715613586

For more information about UCLan's research in this area go to http://www.uclan.ac.uk/researchgroups/ and search for <name of research Group>.

For information about Research generally at UCLan please go to http://www.uclan.ac.uk/research/

All outputs in CLoK are protected by Intellectual Property Rights law, including Copyright law. Copyright, IPR and Moral Rights for the works on this site are retained by the individual authors and/or other copyright owners. Terms and conditions for use of this material are defined in the policies page. 


\title{
Identifying Challenging Job and Environmental Demands of Older Nurses Within the National Health Service
}

\author{
Isaiah Oluremi Durosaiye, MA, MSc', Karim Hadjri, PhD', \\ and Champika Lasanthi Liyanage, PhD' $^{\prime}$
}

\begin{abstract}
Objectives: To explore the existing theoretical contexts of the job and environmental demands of the nursing profession in the National Health Service (NHS) and to investigate how these job and environmental demands impact on the personal constructs of older nurses within the NHS. Background: Nursing is the single most widely practiced profession in the healthcare sector in the United Kingdom. However, nurses contend with challenging job and environmental demands on a daily basis, which deplete them of personal constructs (or resources) required to stay in the profession. Methods: A multilevel exploratory qualitative research design was employed. Ten managers were interviewed for the preliminary study, based on which the three characteristics of an age-friendly NHS workplace were established: health, retirement, and flexibility. Then an in-depth literature review revealed that the most adversely affected job within the NHS was the nursing profession. Finally, a focus group study was undertaken with six older nurses working in the NHS. Results: The most compelling finding of this study is that older nurses would generally not want to stay on the job if they had to work in the ward area. The physical, cognitive, and sensory constructs of older nurses are negatively affected by the job and environmental demands of the ward areas. Conclusions: Understanding how these job and environmental demands of the workplace affect an older nurse's personal constructs may help support a better design of nurse work and the wards and help extend the working lives of older nurses in the NHS.
\end{abstract}

\section{Keywords}

NHS, older nurses, job demands, environmental demands, health and well-being

According to the Health and Social Care Information Centre (2015), nurses make up more than $28 \%$ of the 1.3 million workforce of the National Health Services (NHS) in the United Kingdom (UK). It is the single most widely practiced profession in the healthcare sector in the UK. Beyond this, nurses play a crucial role in the delivery of high-quality healthcare services.

\footnotetext{
' University of Central Lancashire, Preston, UK

Corresponding Author:

Isaiah Oluremi Durosaiye, BSc, MA, MSc, University of Central Lancashire, Corporation Street, Preston PRI IPH, UK.

Email: iodurosaiye@uclan.ac.uk
} 
Ensuring their work ability is adequately supported and sustained is of vital importance for the NHS. With the challenges of an aging population looming, policy interventions to recruit more nurses must be supported by nurse retention strategies that take into account the work ability of the current nursing workforce. Keeping people in work longer has both long-term socioeconomic and short-term fiscal budget ramifications for most developed countries. In the UK, since the abolition of the default retirement age of 65 years in 2011 (www.gov.uk, 2015), employers are no longer allowed to make their employees redundant after they have reached a particular age. Most people can now work for as long as they want to. However, employers in certain professions may still set a compulsory retirement age, if this can be legally justified. Under the new NHS Pension Schemes, introduced on April 1, 2015, NHS employees are required to have worked until the age of 65 before they can qualify for a full state pension (NHS Business Services Authority, 2015), although reaching this age alone does not create a legal justification for retirement. Further conditions, such as minimum pension age of 55 years and maximum age of 75 years, apply to all professions within the NHS, including nursing. For the purpose of this study, an older nurse is a practicing nurse who is 55 years or over, since this is the minimum age threshold above which an NHS employee may be considered for state pension receipt.

The nursing profession is a stressful one (Marshall, Barnett, \& Sayer, 1997; Sharma, Sharp, Walker, \& Monson, 2008). There is an increasing number of nurses exiting the profession prematurely (Frijters, Shields, \& Price, 2007; Shields \& Ward, 2001), a trend that is due to many factors, including the challenges posed by the demands of their jobs and their work environment (Unruh \& Zhang, 2013; Verhaeghe, Vlerick, De Backer, Van Maele, \& Gemmel, 2008). Furthermore, the early exit of nurses from the profession depletes the healthcare sector of much needed experience and knowledge (Duffield et al., 2014). The job and environmental demands of the nursing profession particularly impact older nurses negatively (Heiden, Weigl, Angerer, \& Müller, 2013). With an aging workforce, the adaptations, adjustments, and redeployments that would be needed to address the challenging job and environmental demands of the NHS workplace would require an immense amount of resources from the NHS (Wray, Aspland, Gibson, Stimpson, \& Watson, 2009).

\section{The job and environmental demands of the nursing profession particularly impact older nurses negatively}

In addition, understanding the personal constructs that are generally affected by these work stressors is equally useful to identify the characteristics of the challenging job and environmental demands for older nurses. The personal constructs of older nurses affected by the work environment are those aspects of personal health and wellbeing that serve as resources for nurses, so that they can be functionally fit to perform their jobs (Wang et al., 2015). Personal constructs may take the form of the physical, cognitive, sensory, emotional, and social health attributes required by a nurse to perform their tasks. For example, some studies suggest that deteriorating physical ability and/or declining cognitive acuity together are predictors of nurses' sickness absences (Roelen et al., 2014). From a social personal constructs perspective, extremely acute job demands have been found to have a negative impact on teamwork, which is a key part of the nursing profession (Nelsey \& Brownie, 2012). Furthermore, collegial relationships are also negatively affected if team members' are depleted of their energy resources (Gevers, Van Erven, De Jonge, Maas, \& De Jong, 2010), which could in turn lead to reduced resilience of nurses to job and environmental demands (Cope, Jones, \& Hendricks, 2014). This cause-effect relationship partly explains why nurses rate the ability to act independently of others as a positive element of their job (Unruh \& Zhang, 2013), thereby disregarding the inherent collaborative nature of the nursing profession (Quoidbach \& Hansenne, 2009).

Competing job demands may subject nurses to professional compassion fatigue or burnout (Morrison \& Korol, 2014) and exhaustion (Zito, Cortese, \& Colombo, 2015). Compassion fatigue and exhaustion impair on nurses' physical and cognitive functioning, thus endangering the 
safety of both nurses and patients (Han, Trinkoff, \& Geiger-Brown, 2014; Kirwan, Matthews, \& Scott, 2013). Nurses compassion fatigue may manifest itself in various forms of personal constructs including physical, cognitive, sensory, social, and emotional (Coetzee \& Klopper, 2010).

Furthermore, the environmental demands of their job may support or impair nurses' health, well-being, and productivity at work (Van Bogaert, Kowalski, Weeks, Van heusden, \& Clarke, 2013). Questions have been raised about the adequacy of the physical work environment for the healthcare workers (Mourshed \& Zhao, 2012) and patient safety (Kirwan et al., 2013). The physical layout of medical wards and especially spatial constraints are said to adversely affect the medication communication processes among medical staff (Liu, Manias, \& Gerdtz, 2014). In addition, nurses' negative perception of their work environment is a predictor of their intent to stay or leave the profession (Lamontagne, Levesque, Gingras, Maurice, \& Verreault, 2004).

\section{Objectives}

This section highlights the objectives of this focus group study and briefly describes the findings of the preliminary study, based on which this research study was designed. This focus group study is a follow-up on a preliminary study that revealed the three main aspects of their jobs about which older workers within the NHS are most concerned. These are health, flexibility, and retirement in their respective work environment (Figure 1).

The key finding of the preliminary study is that these three aspects of their jobs must be adequately addressed in order for the work environment to be age-friendly within the NHS. Furthermore, the preliminary study also established that these aspects of older workers' jobs within the NHS will, invariably, affect certain personal constructs of older workers, namely, physical, cognitive, sensory, emotional, and social. A further analysis of these NHS agefriendly characteristics, put in the context of existing literature (Harris, Bennett, Davey, \& Ross, 2010), suggests that this focus group study may be pursued within a research matrix with two dimensions: an age-friendly characteristics

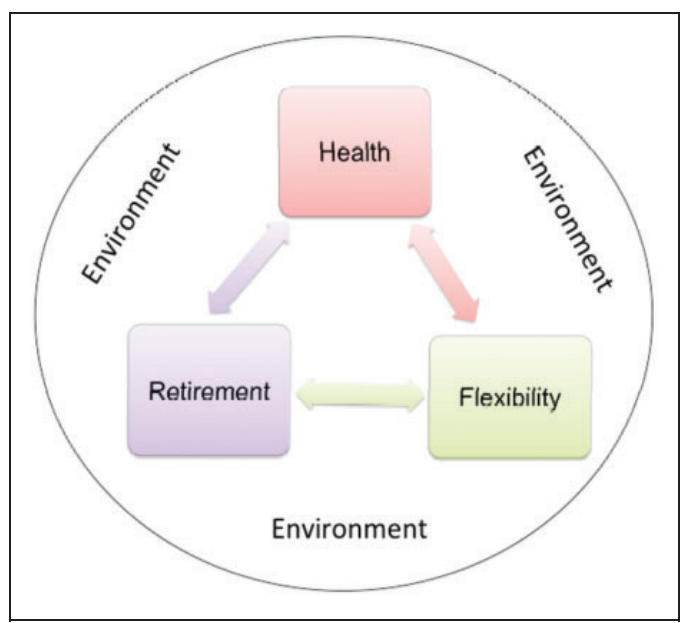

Figure I. Age-friendly characteristics of National Health Service workplace.

dimension and a personal constructs dimension (Table 1), which explores the job and environmental demands of older nurses within the NHS.

The age-friendly characteristics dimension encompasses all the issues that are of concern to older nurses within the NHS (namely, health, retirement, and flexibility), as established by the preliminary study. The personal constructs dimension, on the other hand, includes the physical, cognitive, sensory, emotional, and social aspects of their health and well-being that serve as resources for job performance. The two dimensions are put in context by investigating the correlations between them. The plotting of these two dimensions constitutes the research matrix and thus sets the probable focus group study research domain to be further investigated (Table 1). The overarching aim of this focus group study is to identify the challenging job and environmental demands for older nurses within the NHS, based on the findings of the aforementioned preliminary study. In particular, this focus group study will:

i) explore the existing theoretical contexts of the job and environmental demands of the nursing profession in the NHS and

ii) investigate how these job and environmental demands impact on the personal constructs of older nurses within the NHS. 
Table I. Research Matrix_Based on Preliminary Study.

\begin{tabular}{|c|c|c|c|c|c|}
\hline & \multicolumn{5}{|c|}{ Personal Constructs } \\
\hline & Physical & Cognitive & Sensory & Emotional & Social \\
\hline \multicolumn{6}{|c|}{ Age-friendly characteristics } \\
\hline Flexibility & \multicolumn{5}{|c|}{ Probable Focus Group Study Domains } \\
\hline
\end{tabular}

\section{Literature Review and Theoretical Contexts}

This section reviews existing literature relevant to nursing and the overall job and environmental demands of the nursing profession, after which the key task domains older nurses perform in a typical ward setting are identified. Then nurses' health and well-being and their relation to individual circumstances are discussed, with a focus on work ability. Further, the theoretical contexts underpinning the job and environmental demands of nurses are explored and how these impact on older nurses' personal constructs is investigated.

The nursing profession is pivotal to the healing and care activities undertaken in most areas and departments within the healthcare system. Nurses work in various functions, which can range from very physically demanding, such as staff nurses in wards, to more sedentary, such as occupational health and other specialist nurses. Nurses can also be found in fast-paced acute care settings, in the cognitively demanding intensive care units, and the emotionally exhausting oncological or palliative care units. There is sufficient research evidence to suggest that within the nursing profession, staff nurses working in ward areas are at risk of experiencing work-related distress due to the combined effects of extreme job and environmental demands (Adams \& Bond, 2000). The adverse effects of a disabling work environment may be particularly severe for older nurses working in this area.

The interactions between older nurses and their work environment rest on the theoretical premise of the person-environment fit theory proposed by Lewin (1951). This theory was furthered by the environmental docility hypothesis (Lawton \& Nahemow, 1973), which posits that environmental stimuli have a greater demand quality as the competence of the individual decreases. In this focus group study, environmental "stimuli" and/or job demands are conceptualized in the context of the tasks nurses perform relative to the appropriate level of competence required to perform these tasks.

\section{The Nursing Profession and Tasks}

Nurses provide round-the-clock care and services for their patients, requiring them to work in shifts. Like most other professions in the UK, there is a 48-hr per work week limit for nurses. However, there is also a provision for nurses to opt out of this restriction and work more hours on a weekly basis, if they so wish. Most nurses do 12-hr day or night shifts, but there are shorter shifts of $8-\mathrm{hr}$ workday and longer shifts of 14 hours a day. Planning and managing the nursing task activities over a continuous 24 -hr period are challenging for both the NHS management and the nursing profession (Royal College of Nursing [RCN], 2012). Dendaas (2011) purports that there are four main task domains in which nurses in acute care settings work: surveillance, care execution, patient/family support, and care integration. The physical environment exerts some degree of influence on a nurse's ability to perform these tasks. Dendaas' study postulates that “... environmental congruence is the capacity of the work environment to promote a good fit between workers and the physical environment ..." (2011, p. 25). Given all other conditions (e.g., job demands), it is the level of competence afforded an individual to perform these tasks that measures up to the interplay between the environmental demands and the personal constructs. Ideally, 
these interactions will be in congruence provided the severity of the environmental demands does not surpass the worker's ability, which is manifested in various forms of personal constructs.

The first task domain is surveillance. This is the degree to which patients can be seen or heard by nurses, as afforded or supported by the personal constructs of the nurse and the environmental demands of the ward area. The second task domain is care execution, which is the extent to which nurses may attend to their patients without any physical barriers or impediments. This includes, but is not limited to, the provision of personal care in bathrooms and the existence of clearance areas for the use of wheelchairs and other mobility equipment around patients. Patients and family support are the third task domain and are the degree to which the physical environment in the hospital facilitates nurses' ability to support patients and their family in their psychosocial needs. This task domain encompasses the availability of areas where patient's treatment or care plan can be discussed in privacy. The fourth task domain ward nurses perform is care integration, which consists mainly of the administrative tasks that are performed away from patients but, nonetheless, are important for patient care. This includes automated systems and technological support for nurses' tasks in the ward area. How well the physical ward environment facilitates or impedes nurses in the performance of these tasks is termed functional congruence by Dendaas (2011).

Health, flexibility, and retirement are three key characteristics of an age-friendly workplace within the NHS. The nursing profession appears to be the main job type that is most adversely affected by these characteristics of an agefriendly workplace within the NHS. The ability of an older NHS nurse to perform their tasks will depend to a large extent on how the work environment supports them in these respects. While these three aspects of the workplace are all crucial for older nurses, health has been found to be the major enabler or disabler when it comes to older nurses performing their daily tasks and a pivotal predictor of their intention to continue working (Letvak, 2005).

\section{Health and Well-Being at Work}

There is a school of thought that posits an unequivocal stance that there is a direct relationship between nurses' objective and subjective health and their work environment (McNeely, 2005). To understand the interaction between nurses' health and their work environment, it is first important to define what "health" is. According to the World Health Organization (WHO, 1948), "Health is a state of complete physical, mental and social well-being and not merely the absence of disease or infirmity." While this definition appreciates the fact that the absence of disease is not sufficient to imply an individual's wellbeing, it fails to establish a broader platform to discuss health in other contexts that may be person or environment specific. A more comprehensive definition of health as proposed by Bircher (2005, p. 336) states, "Health is a dynamic state of wellbeing, characterized by a physical, mental and social potential, which satisfies the demands of a life commensurate with age, culture and personal responsibility." Bircher's approach offers a broader foundation for discussing health and related issues in the sense that, instead of providing a platform for absolute and general criteria to determining health, it rather suggests nonuniform but coherent dimensions relative to the individual context. Moreover, the explicit reference to the dynamic nature of health offers plausible grounds to infer its variability across such domains as age, culture, and personal responsibility. This definition also allows for diversity that may be due to individual circumstances such as job and environmental demands. Hence, health may be viewed as a person's ability to achieve or exercise a cluster of basic human activities or capabilities in as much as those capabilities are considered relative to individual contexts such as age, gender, or sociocultural circumstances (Wang et al., 2015).

This suggests that nurses in the same setting may react to the same environmental stimuli differently due to their individual state of health. Hence, subjected to the same level of job and environmental demands, nurses may respond differently and to differing degrees. Health, therefore, has an unambiguous bearing on an individual's quality of life and standard of living 
(Pisarski \& Barbour, 2014). Other studies have shown that older nurses may be subjected to physical health injury due to ill-designed jobs and adverse environmental demands (Baptiste, 2011). However, very few studies have been conducted that illuminate the interplay between nurses' job demands and environmental demands, and what their cumulative effects are on the personal constructs of older nurses. Those studies that have looked into this topic in depth do suggest strong dependency between the three variables (Soer, Hollak, Deijs, van der Woude, \& Reneman, 2014). In particular, it is widely held among researchers that the job and environmental demands on older nurses have profound consequences on three of their personal constructs which are predictive of health and work ability, namely, physical, cognitive, and sensory (Lara et al., 2013).

If a person's state of health and well-being must be understood as multidimensional and as being relative to objective attributes such as age, a worker's ability to perform certain tasks at work must thus be seen as concomitant with health and well-being. This focus group study explores how the job and environmental demands of the workplace affects these three personal constructs (i.e., physical, cognitive, and sensory) of older nurses within the NHS. The theoretical contexts underpinning the interactions between the job and the environmental demands of older nurses and their personal constructs are presented in the following sections.

\section{Job Demands}

Job demands are the visible and latent aspects of a job that require a degree of personal constructs and/or organizational resources to manage (Bakker, Demerouti, \& Verbeke, 2004). The demands of a job may manifest as time pressure, workload, or conflicting requirements (Demerouti \& Bakker, 2011). Nurses face various types of on-the-job demands, stemming mainly from the relationships or transactions between their personal constructs and the characteristics of the work environment (job and/or environmental demands of the workplace). Furthermore, neck and shoulder pains are the most prevalent forms of musculoskeletal disorders (MSDs) among hospital nurses, which may be caused by pushing, pulling, reaching, and stretching in patient handling tasks (Smedley et al., 2003). More recently, research has shown that cognitive workload has a direct influence on the prevalence of MSDs among hospital nursing staff (Habibi, Taheri, \& Hasanzadeh, 2015).

Job demands are not necessarily negative in nature or in their outcomes. Some research studies show that certain types of job demands are particularly motivating with positive outcomes and better employee performance (Van den Broeck, De Cuyper, De Witte, \& Vansteenkiste, 2010). However, persistent exposure to excessive or increased job demands is known to be detrimental to employee health and job performance (Meijman \& Mulder, 1998). Yet earlier research into the relationship between job demands, job control, and job strain have proven that it is not high job demands in itself that constitute job strains in employees but rather the lack of adequate control or resources to manage the job demands that causes job strains (Van Yperen \& Hagedoorn, 2003). This idea is buttressed by Karasek (1979) who suggests that there are two important elements of the work environment that are necessary for job strain to come to play, that is, the job demands placed on the individual and the discretion permitted to the worker on how to meet these demands. The ability of the employee to mediate challenging job demands has been linked to loyalty and intrinsic job motivation (Jourdain \& Chênevert, 2010). As a result, a job high in demands but that is, nevertheless, afforded a proportionate amount of decision latitude or control could lead to a worker's increased sense of competence and productivity (Dollard, Winefield, Winefield, \& Jonge, 2000). However, this approach has been criticized due to its simplistic explanations of the many aspects of a job in the complexity of a work environment (Bakker, van Veldhoven, \& Xanthopoulou, 2010).

In the job demand-resource (JD-R) model, Bakker and Demerouti (2007) postulate that job demands are initiators of a health impairment process, while job resources are initiators of a motivational process. According to the JD-R model, every occupation has its own inherent risk factors that are predictors of job-related stress. 
The physical, psychological, and emotional aspects of the job that require sustained effort are categorized as the job demands (Hall, Dollard, Winefield, Dormann, \& Bakker, 2013), while the job resources are the energy reservoirs that an employee may resort to when faced with overwhelming demands (Hobfoll, 1989, 2002). Job resources are mediating factors to the negative effects of job demands like stress (De Jonge \& Dormann, 2006). Hence, job resources should be proportionate in their quantity (Bakker, Demerouti, \& Euwema, 2005) and quality (Lavoie-Tremblay, Trépanier, Fernet, \& Bonneville-Roussy, 2014) of physical, psychological, social, or organizational dimensions to fulfill these functions in the workplace. High job demands, as attributable to the nursing profession, may therefore impact negatively on health and well-being; the activation of functional and corresponding types of job resources, on the other hand, may mitigate the effects of these job demands (Van Den Tooren \& De Jonge, 2008).

\section{Environmental Demands}

Environmental demands consist of all the physical aspects of the work environment, in particular the design and management of the work space including accessibility, thermal comfort, ambient lighting, signage, acoustics, visual effects, and color coordination (Djukic, Kovner, Budin, \& Norman, 2010). A number of studies have documented the positive impacts of the built environment on the healing and care of patients (Abbas \& Ghazali, 2012; Gross, Sasson, Zarhy, \& Zohar, 1998). Other studies have established that there is a significant relationship between nurses' perceptions of the characteristics of their work environment and quality of care provided to patients (Hinno, Partanen, \& Vehviläinen-Julkunen, 2011). However, there is quite a dearth of research studies that have explored how the design of the physical workplace may support older nurses' health and well-being. When the physical aspects of the work environment have been the focus of study, the resultant impact this has on nurses and other healthcare workers has been inconclusive (Huisman, Morales, van Hoof, \& Kort, 2012).
One of the greatest environmental demands older nurses face in the workplace within the NHS is insufficient and functionally inadequate spatial work space for moving and handling task performance, such as patient bathing (Hignett \& Evans, 2006). A study conducted to understand how nurses' perception of their work environment influences patient moving and handling revealed that nurses perceive bathroom transfers as the most difficult type of moving and handling, with three of the four significant transfers associated with this location (Holman, Ellison, Maghsoodloo, \& Thomas, 2010). A poorly designed work space may also slow down patient healing process to the extent that it takes away valuable time that nurses can spend with patients for therapeutic care (Page, 2004).

In recent times, a growing body of knowledge has informed the design of healthcare facilities, with the primary goal of facilitating the treatment of patients within the NHS (Douglas \& Douglas, 2005). Consequently, a number of best practice designs of the ward environment targeted at facilitating the healing and managing the health conditions of patients and service users have been implemented. An example is the recent refurbishment of a dementia ward in an NHS hospital in Northwest England (NHS LTHTR [Lancashire Teaching Hospital Trust], 2015). However, because the intended recipients of the services offered by these innovative designs were not usually the workers in the healthcare sector, there is little research evidence to substantiate how beneficial these designs have been for NHS healthcare workers. Environmental demands of the workplace within the NHS may thus be inadvertently adversely impinging the personal constructs of NHS older workers, while hitherto, existing research studies of their effects on the health and well-being of older nurses are rather ambiguous and inconclusive. What can be ascertained at this stage is that the design features of the physical environment have a significant impact on the health and well-being of older people (Biggs \& Haapala, 2015).

While the characteristics of an age-friendly workplace span across themes such as health, retirement, and flexibility (Table 1), health seems to be of greater significance for older nurses than 
the other two. Furthermore, of the five personal constructs identified in the preliminary study, the three most prevalent are physical, cognitive, and sensory. These three themes seem to be of significant importance and are thus worthy of further investigation. Also, although one of the most comprehensive accounts of nursing tasks in a ward setting and how they are affected by the physical environment is the one given by Dendaas (2011), it does suffer from a number of flaws. Among others, Dendaas failed to expand on the dynamics among nursing staff and other healthcare workers. Furthermore, the degree to which the job design and the work space design may be integrated has not been adequately addressed. Hence, there are limitations on how far these task domains may be applied across various settings.

This study explores the various types of job demands NHS older nurses face and how these, in conjunction with environmental demands, may affect the health and well-being of older nurses, with a particular focus on the physical, cognitive, and sensory aspects of their personal constructs.

\section{Method}

This research sought to explore the impacts the job and environmental demands of the workplace have on older nurses within the NHS based on the interactions between older nurses and their work environment. The methodology employed for this exploratory study was a focus group. The intent of this approach was to allow for flexibility in how participants identify the issues that affect older nurses within the NHS, with the possibility to explore newer topics that may be generated during the focus group discussion. According to Krueger and Casey (2009), focus group discussions are most suitable in an environment where the participants feel comfortable, respected, and free to express opinions without being judged. Focus groups promote self-disclosure among participants on a given topic of discussion by building on the group dynamics (Freeman, 2006). It requires a sensitive moderator and, if effectively facilitated, a focus group generates richer data and gives more depth to the understanding of the topic of discussion compared to individual interviews (Kaplowitz \& Hoehn, 2001).

Undertaking a focus group as a means of data collection is not an alternative to individual interviews or participant observation. If well conducted, a focus group may delve into a topic in greater depth than an interview. However, it does not fully replicate the context that can be achieved in the observation of participants (McLafferty, 2004). For instance, in an interview setting, the researcher queries the respondent on a given topic and relies on their openness, knowledge, and memory recall of the lived experience. A focus group goes a little further due to the multilateral interaction among participants by building on the group dynamics because participants may question their peers' presumptions and thus further expand the premise of the discussion. In social science research, focus groups are particularly useful in the healthcare sector. Focus group discussion has been applied as a means of data collection from practicing nurses in nursing homes and homebased care settings (Carlson, Rämgård, Bolmsjö, \& Bengtsson, 2014).

This section presents the methodological considerations and approach employed in the research. The preparation and the research design are explained; then the sampling, piloting, and data collection methods; and, finally, the data analysis and synthesis are elaborated on.

\section{Preparation and Research Design}

The scene for the focus group was set by a preliminary study, which interviewed 10 participants from NHS. These participants were from various backgrounds, including occupational health advisors, human resource managers, facilities' managers, and practicing older nurses. The preliminary study was conducted to establish the characteristics of an age-friendly workplace within the NHS by identifying the prevailing factors that compromise or support the health of older workers within the NHS. The major findings of the preliminary study were the following: 
a) health, flexibility, and retirement at work are the three main characteristics of the workplace of which older workers are apprehensive within the NHS;

b) a review of the literature suggests that these characteristics of the workplace may potentially affect five major personal constructs of older nurses in the workplace, namely, physical, cognitive, sensory, emotional, and social (Table 1); and

c) the most critical profession within the NHS that is affected by workplace characteristics are older nurses due to their number and significance in the healthcare service delivery (Nolan, Grant, Brown, \& Nolan, 1998).

The research matrix in Table 1 was plotted to gain an overview of the major characteristics of the workplace according to the preliminary study and understand how these correlate with existing literature in terms of the personal constructs that are consequently affected. Also, the literature review revealed that the personal constructs that are most affected are physical, cognitive, and sensory and the group of employees mostly affected are older nurses (Fitzgerald, 2007). However, a further review of the literature suggests that health is the most crucial workplace characteristic that impacts on older nurses, based on which they may continue to work or exit the profession (Wright, 2014). These key findings, from both empirical data and literature, gave enough premise to further the study by exploring health as a theme along with the three personal constructs (i.e., physical, cognitive, and sensory) in the current focus group study (Figure 2). The topics of discussion for the focus group were designed based on the results of the preliminary study. The focus group questions were piloted through an interview that was aimed at testing its relevance and effectiveness. The participant who volunteered for the pilot is a practicing specialist nurse with more than 20 years of work experience as a nurse. The participant for the pilot interview suggested minor modifications to the questions, which were implemented before the study was conducted. Table 2 provides a sample of the focus group questions.

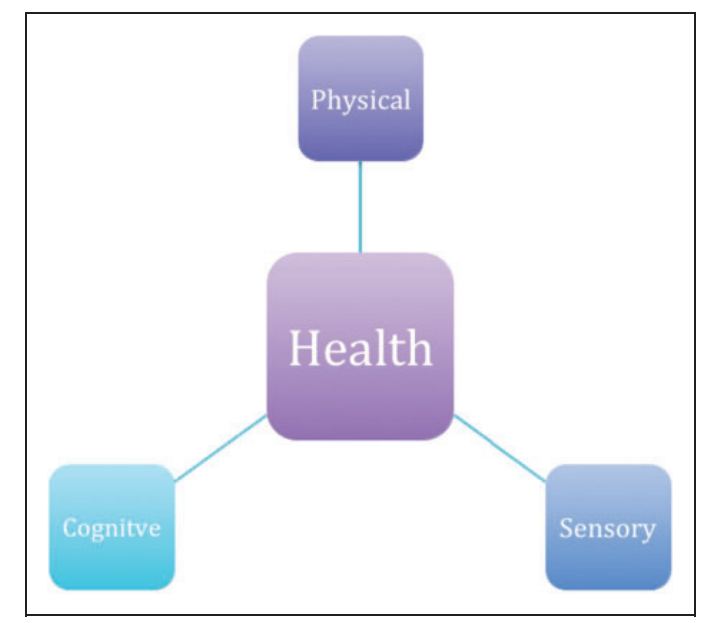

Figure 2. Health and the personal constructs.

\section{Sampling}

The sampling of participants in this focus group study was a follow-up from the preliminary study. Ten participants in managerial positions were interviewed in the preliminary study. However, the participants in this focus group study were entirely different from those that took part in the preliminary study. Participants were recruited from the NHS. Potential candidates were identified through a contact person within the research and innovation department of the NHS, who posted a call in the internal communications network, and solicited for volunteers. This approach ensured that employees' privacy was not intruded and that only volunteers who showed initial interest were subsequently contacted. Those volunteers who showed interests in participating in the study were sent the participant information sheet which detailed the aims and objectives of the study and why their contribution was needed. A total of six nurses were recruited for this focus group study.

The findings of the preliminary research suggest that older nurses are the largest population of employees who are most adversely affected by the identified characteristics of the workplace within the NHS. While one of the key areas of exploration in this focus group study is the impact the work environment has on older nurses, participation in the focus group was not restricted by age. The reason for this is twofold. First, 
Table 2. Exploratory Focus Group-Question Schedule.

I Please tell us your current position/job title, and your main tasks and responsibilities?

2 How long have you worked for the NHS and how long have you been in your current position?

3 What do you understand by the term an age-friendly workplace?

4 Job-positive elements: What are the five major tasks of your job that have the greatest positive impacts on your health and how?

5 Job-negative elements: What are the five major tasks of your job that have the greatest negative impacts on your health and how?

6 Ergonomics: Please name the five ergonomic features of your job that have the greatest impact on your health, and in what ways (e.g., application of undue force, monotonous, or frequently changing tasks)?

7 Design of the physical environment: Please name the five design features of your workplace that have the greatest impact on your health, and in what ways (e.g., estates and wards layout, accessibility of work areas, ambient lighting, signage, color coordination, and thermal comfort)?

8 (A) Physical: Do you or any practicing nurse above the age of 50 that you know of have any physical limitations (e.g., mobility, posture, dexterity, and grip strength)?

(B) Physical: How do these physical limitations affect your (or your colleague's) daily routine? Examples?

9 (A) Sensory: Do you or any practicing nurse above the age of 50 that you know of have any sensory limitations (e.g., visual, auditory)?

(B) Sensory: How do these sensory limitations affect your (or your colleague's) daily routine? Examples?

I0 (A) Cognitive: Do you or any practicing nurse above the age of 50 that you know of have any cognitive limitations (e.g., way-finding, memory, and concentration)?

(B) Cognitive: How do these cognitive limitations affect your (or your colleague's) daily routine? Examples?

II (A) Retirement: Do you see yourself retiring as a nurse? If yes, why? If no, why not?

(B) Retirement: What age do you think is the most ideal for you to retire?

12 What is your vision for the future of nursing?

13 What are the major points of this discussion that you wish could be put into action?

Note. NHS = National Health Service.

participants were asked about both their personal experience and what they had observed happening in their practice. So even if a participant had not had personal experience of the question, they were encouraged to share personally observed situations in their work environment. Second, it was important to be aware, and reduce the risk, of exclusion of valuable opinions if there was an age restriction to participation. All the participants for the focus group session were either staff nurses or senior healthcare assistants. All the participants gave their written informed consent to take part in the study and agreed that anonymized quotes may be used from the focus group discussion to ensure confidentiality in accordance with the U.K. Data Protection Act (legislation.gov.uk, 2013).

\section{Data Collection}

To have a relaxed and conducive environment, the focus group was conducted on-site at the participants' workplace. A dedicated room was provided for the focus group session, so as to avoid distraction from other members of staff or patients. At the beginning of the session, the researcher ensured that all the participants were aware of why the focus group was being undertaken and what the objectives of this particular session were. Before the data collection exercise could commence, the researcher invited all participants to read the participant information sheet. Participants were asked whether they had any questions regarding the study. The researcher responded to all questions and ensured that all the participants were at ease with their participation in the study. After all issues were resolved, each participant was invited to read and sign a consent form to evidence their voluntary participation in the study.

To stimulate ideas and encourage participants to start talking, a short video was shown about the topic. The video lasted approximately $3 \mathrm{~min}$ and was intended to give participants an idea of the 
demographic situation in the UK, including current discourses on policies and practices with respect to the NHS. A PowerPoint presentation was also used to aid and facilitate the discussion. At the beginning of each question, the question came up on a slide so participants could refer back to it during the discussion. This helped to keep the discussion focused and on track.

The researcher's work was supported by an assistant who helped with the setting up of the audio and video recording facilities. The assistant also helped to take notes by writing participants' responses on a flip chart as the discussion progressed. However, the assistant did not interfere with the focus group in any other way. The audio and video were recorded and safely stored in accordance with the university regulations and the ethical approval for the study. The audio and video recording were transcribed for analysis.

\section{Data Analysis and Synthesis}

The analysis was conducted both manually and with the aid of NVIVO software NVIVI 10 for Windows. Manual thematic analysis was used to identify the themes, trails, and interconnections. To reduce the effects of bias and support the robustness of the data analysis, a colleague from the same department as the researcher was asked to independently code and review the transcripts. This member did not take part in the preparation of the focus group questions and was not present at the focus group session.

As was suggested earlier, the questions for the focus group were designed to capture participants' opinions and experience about the impact their jobs as nurses have on their health. While the intention of the focus group was to explore health (as was previously established in the preliminary study), the questions were actually related to other aspects of older nurses' jobs that may impact on their health. This approach was employed to avoid providing a cue to participants as to what the focus group intended to glean from them.

\section{Results}

The second objective of this exploratory focus group was to investigate how job and environmental demands impact on the three main personal constructs of older nurses (namely, physical, cognitive, and sensory) within the NHS. It must be appreciated that health was a recurring theme in the data analysis. At the initial stage of the coding, the four main themes that were explored in the data analysis were the personal constructs, environmental demands, job demands, and health. Some of these were subdivided into subthemes as shown in Figure 3. Further into the analysis, "ward" emerged as an important and a major theme that needed to be explored in greater detail. Ward was then analyzed in the context of the other personal constructs, health, job, and environmental demands.

A summary of the thematic analysis of the focus group transcription suggest that the most challenging work area within the NHS for older nurses are the wards. The prevalence of four personal constructs was reinforced in the study, namely, physical, cognitive, sensory, and emotional. However, the severity of the ward work on these constructs varies. While the physical construct predominates over the other three, the cognitive constructs also seem to have a significant impact on the work ability of older nurses. These relationships are depicted in Figure 4, where the cumulative effects of ward work are presented (as personal constructs) alongside the severity level of each personal construct identified in the study (Figure 4).

This section presents the findings of the study by discussing the nature of older nurses' work in the wards and the impacts job and environmental demands have on the personal constructs of older nurses.

\section{Older Nurses and Ward Work}

The most compelling finding of this study is that nurses will not stay in the job as they get older if they have to work on the wards. There is a general impression and expectation from colleagues that as they get older on a ward, an older nurse should move on to 'a more sedentary role'. Hence, older nurses may be stressed striving to "live up to such expectations," as those who stayed longer are treated as performing poorly at their job. This is what a participant had to say regarding this: 


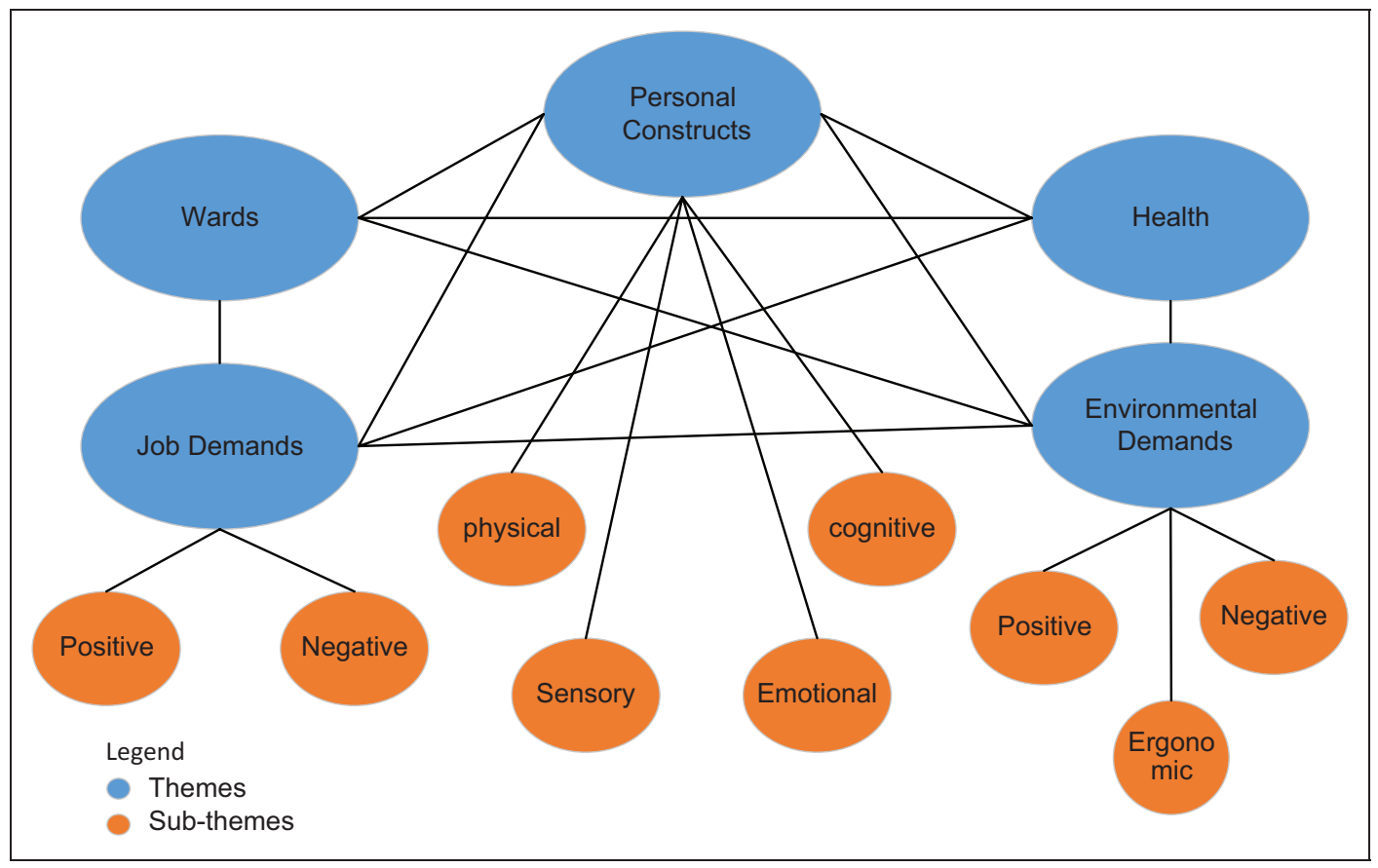

Figure 3. An overview of the thematic analysis.

... The other thing is that people naturally assume $\ldots$ if there's an older nurse on the ward who is a staff nurse, she's still a staff nurse at that age because she's perhaps not very good at what she's doing. Most people by that age would have moved on....

This trend seems to be creating a vicious cycle as nurses soon begin to realize that most of their contemporary colleagues have left or are leaving the wards. It is interesting to note that while most of the participants were not themselves working on wards, their opinions about ward work regarding older nurses were unequivocal. The following are the five most frequently cited reasons by participants on why older nurses may leave the ward or the profession earlier.

Moving and handling. The dynamic nature of the ward environment is compounded by the physicality of the tasks nurses perform on wards. There is a frequent need to move patients around and, even with the right equipment, a substantial amount of physical effort may still be necessary to transfer patients from one functional location

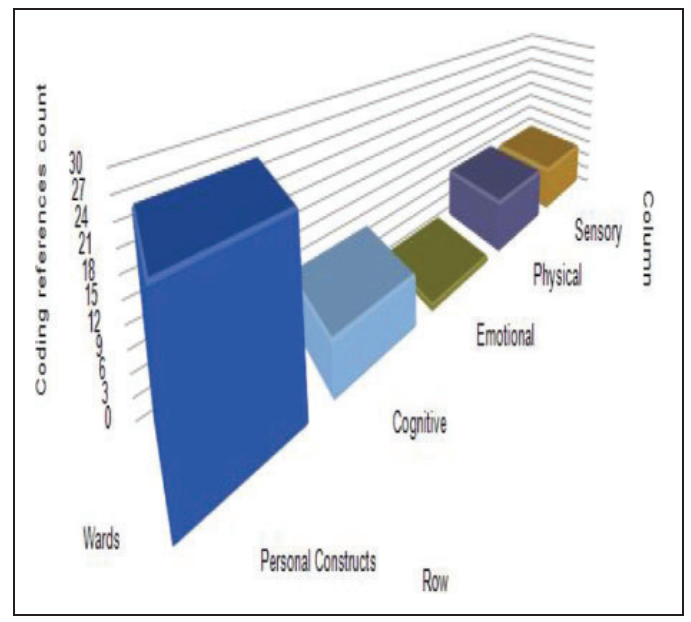

Figure 4. Impacts of ward work on the personal constructs of older nurses.

to another, for example, from a wheelchair into a bathtub:

In my particular role there's not as much moving and handling, and heavy work as there would be on the wards ... 
The physicality of the ward work is further exacerbated by the fact that with an aging population, nurses are having to deal with patients who are in worse health conditions on average than was the case some years ago. Patients are now almost invariably very poor, which means they require high-level nursing. This has resulted in increased demands on the healthcare services and the physical effort required in providing adequate levels of nursing. As suggested by a participant:

... It is hard now because of the nature of the patients coming, they're all really poorly.... It's more demanding mentally, physically, definitely....

Nurses who provide personal care, like bathing, may have to contend with unhealthy posture, including stretching and reaching. This may increase the risk of sustaining musculoskeletal injuries and may result in sickness absences and, eventually, in premature exit from the profession. While unaided lifting of patients is not permitted within the NHS (HSE [Health and Safety Executive], 1992), lower back injuries due to patient moving and handling have long been of major concern to the nursing profession in the UK (Hollingdale, 1997), although there is evidence that affected nurses may not have taken time out and the incidents might have remained unreported (Barnes, 2007). Wilson (2001) suggested a fourcomponent approach to safer handling practice:

- encouraging clients to assist in moving themselves;

- an ergonomic assessment to the load, including the ability of the person needing to be moved, the task, the individual doing the moving, and the environment;

- the use of equipment to lift and move highly dependent clients; and

- a multifaceted training program with ongoing support for staff.

Adhering to these procedures is expected to reduce the risk of sustaining MSD injuries.

Pace of work. As nurses get older, they may realize that they cannot keep up with the pace on the wards anymore, and if they will have to do the same job until their late $60 \mathrm{~s}$, then they would rather move on to other less demanding jobs while they still can. The ward area is a fastpaced work environment. Even without any form of physical disability, older nurses may experience reduced mobility over time as a natural process of aging. Reduced mobility in a constantly fast-paced environment may result in lower productivity:

... I think nurses are so used to being independent and healthy and working at such a fast pace. When you know you're not doing that anymore, you start to feel a bit cumbersome in your team and so I think people move on....

It has been reported that medical staff working in emergency assessment units have a strong preference for fast-paced and unpredictable work environment (Annandale, Clark, \& Allen, 1999); however, these employees also emphasize the need for decision latitude in their roles (Karasek, 1979). The lack of control over their tasks and work flow is said to subject nurses to undue mental stress (Bourbonnais, Comeau, Vézina, \& Dion, 1998). Exposed to an intense pace of work, older nurses may have to make the hard choice between maintaining their independence and thereby running the risk of reduced productivity and work-related injury, or moving on to less demanding roles within the organization to keep their jobs. However, participants also pointed out that older nurses may be desperate to keep their jobs, even if by so doing they become a burden to their colleagues. As suggested by a participant:

... I've had a couple of elderly staff as well going back and it was two work ladies that couldn't afford to give up work. So, I had one when I was healthcare assistant and I was on nights. She only worked nights. However, having her on nights, with it just being the two of us, it was all down to the other person, because ..., you know? I am talking (when I was) seventeen years of age on a very heavy ward

In a fast-paced ward environment, the need to attend to immediate patient needs may override considerations for personal safety, which may make nurses more prone to work-related injuries 
(Mark et al., 2007). As a result of this situation, older nurses, at the very least, may soon begin to feel so stressed in their roles that they tend to opt out after a while.

Risk of clinical error. There is also the tendency that with real or perceived reduced work ability older nurses may constitute a risk factor to patients' health and safety. Older nurses working in wards are therefore also apprehensive of the consequences the demands of the ward work would have on their practice. In particular, they are concerned that if they stayed longer on the ward, they may face a higher risk of committing a clinical error and consequently losing their license, due to the job and environmental demands in the wards. A participant noted:

... I would be worried about my nursing registration. I'd be worried about making a mistake. I think that is probably one of the reasons why a lot of them come off the wards - they're aware that their functioning is slower, so they don't want to be in that situation when something goes wrong ...

Medication errors in England and Wales account for $9.68 \%$ of all patient safety incidents reported between January 1, 2005, and December 31, 2010 (Cousins, Gerrett, \& Warner, 2012). A literature review of the circumstances around medication errors shows that some authors have attributed the risk of medication error in ward environment to being the result of poor adherence to protocol and poor calculation competency (Jones, 2009; O'Shea, 1999) among nursing staff, whereas other authors are of the opinion that medication errors are mainly due to systemic deficiencies, which only manifest at an individual level (Anderson \& Webster, 2001). Further research is necessary to help understand the interplay between individual and systemic failures. While a significant amount of attention has been given to the risk of physical manhandling of patients, it seems likely that the risk of error in the application of medication is also of great concern to practicing nurses. Hence, rather than wait for the worst to happen, older nurses might make a voluntary switch to another role.
Collegiality and teamwork. Ward work requires a great amount of collegiality and team collaboration. However, nurses who work in shifts tend to work with different colleagues from time to time, which reduces collegiality and team collaboration. The lack of a cohesive atmosphere could mean that workers on the ward may not support each other as readily as people working in teams would be expected to do. A participant not working on a ward expressed their views about team collaboration on wards as follows:

... I don't think you get that support on the ward. It's not the same set of people working together every day. It's literally depending on shift work, isn't it? So, I don't think you get that kind of support....

Team collaboration, on the other hand, is crucial to the functional management and operation of ward activities. In their primary role as providers of patient care, nurses are mutually dependent on support from their colleagues and should be cognizant with the ward work environment, to be able to attend to prompt patient needs. In a study conducted to explore the activities of nurses in a mental ward setting, teamwork has been found to have an overarching impact on the performance of the ward (Deacon \& Cleary, 2013). In the absence of a cohesive team, collaboration may not be readily forthcoming, which may lead to increased workload for older nurses, thus exposing them to excessive and undue stress (Pisarski \& Barbour, 2014). This could easily result in them moving on to another role or translate into their premature exit from the profession.

Continuous professional development. To ensure that patients are treated safely, nurses must be up to date with their professional trainings. However, in a fastpaced ward environment with competing priorities, mandatory trainings are more likely to be canceled:

... I think in this Trust, there is a real problem with nurses having their mandatory training. Just because the pressures on the ward are so high that they are not able to release them. Things like manual handling and every nurse should be able to do those sorts of (training) .... 
Lifelong learning is important for the nursing profession, especially in the face of an aging workforce (Jarvis, 2005). Research has shown that nurses invariably appreciate the importance of undertaking CPDs (Continuous Professional Development) for their career and practice (Drey, Gould, \& Allan, 2009). However, organizational atmosphere, including excessive workload and lack of managerial support, and personal circumstances, such as balancing doing CPD with work and life outside work, may distract practicing nurses from their studies (Gould, Drey, \& Berridge, 2007). Even when nurses do make it to the trainings, some of the trainings may not be adequately designed, and as such may not be fit for purpose. Participants in this focus group study appreciate the need for training but noted that some of the trainings are detached from real-life situations:

I don't think the training always reflects working with a real patient. You're working the training on an able-bodied person, and there is a big difference between that and a patient....

Older nurses may therefore still be exposed to the risk of work-related injury, even if they have complied with the requirement to undertake their mandatory training. A nuanced approach to training may be more appropriate for older nurses compared to their younger counterparts; this does not detract from the need to train nurses regardless of age (Pool, Poell, \& ten Cate, 2013).

There is an overwhelming consensus among the participants that the ward, as a work environment, is not very accommodating to older nurses. Participants seem to invariably have a negative opinion about ward work, even if they themselves are not working on wards. It was generally acknowledged that the job and environmental demands for nurses working on wards are the most challenging. Participants do not seem to think that there will be too many older nurses left working in the wards, because as nurses age, they tend to move on to less demanding roles within the NHS.

\section{Job Demands and the Personal Constructs}

The demands the ward tasks place on the various aspects of an older nurse's personal constructs were explored. The three personal constructs investigated were physical, cognitive, and sensory. Participants were invited to express their views on any preexisting physical, cognitive, and sensory limitations, and how these may be affecting their daily routines as a nurse.

The negative effects of job demands on wards are most pervasive on the physical constructs. Therefore, it must be appreciated that even with the most appropriate equipment and training, there is an inherent physicality to the nursing tasks that cannot be completely eliminated. This also suggests that there may be the need for nurses to apply undue force in the performance of their daily duties due to inappropriately designed tasks, or as a result of inadequate equipment. This may mean that older nurses will have to contend with lifting, pulling, pushing, and stretching, which may have physical health implications. Nurses may tend to live with physical injury, sustained by working on the ward, over their career time without any chance of permanent recovery:

... obviously I am thirty-five and I've been in the job for sixteen years. The damage it's done to me now, I had a bad back when I was eighteen, from working on an orthopedic ward....

If physical limitations do exist, older nurses may either be restricted in the type of tasks they can perform or be more dependent on the support of their teammates. However, in a ward environment such support may not be readily available. Hence, the extent to which the job demands cause physical limitations may determine whether or not an older nurse decide to remain on the ward.

Wards, as a work environment, are busy. Parallel activities may distract older nurses from key tasks requiring intense cognitive resources. The interactions among the medical staff and between the other healthcare workers and patients in an open bay have an intruding impact on the surrounding environment. However, whereas the existence of physical limitations may be more evident, the prevalence of cognitive limitations may not be readily recognized, even by the affected person. There is an acknowledgment by participants that cognitive acuity of older nurses may diminish with age: 
... I don't concentrate as well as I did when I was younger....

Older nurses may find it harder to stay focused and concentrate even on tasks requiring minimum levels of cognition. For example, research has shown that time management skills, which are crucial in staff management, are adversely affected by diminishing cognitive resources (Haight \& Belwal, 2006). This supposition is supported by a participant's response:

... Certainly it affects time management. So even some simple things like making sure your staff go on break, you know....

Diminished concentration capability is further exacerbated by shift work, which has proven to be an important factor that impairs older nurses' cognitive work ability (Berger \& Hobbs, 2006). Shift work also has a negative impact on sleep pattern. So as people get older, and they tend to sleep less well anyway, any disturbance to their sleep pattern will adversely affect their cognition (Yaffe, Falvey, \& Hoang, 2014). Shift work poses a huge job demand on all healthcare workers by impeding concentration levels. However, for older nurses working in wards, this problem is exacerbated by other job demands like the fastpaced work flow.

... I think generally even if they are not over 50, they'll certainly be working shifts. And we are working long days and working nights. You do have certain cognitive limitations, anyway....

Decline in concentration level will in turn affect certain activities that require a high level of cognitive resources. For instance, it may reduce the ability to make the right judgment on some crucial issues and thus may impede patient safety:

... Maybe allocation of patients, maybe it can affect that, you may be putting a non-supported junior staff member looking after a very sick patient. It is kind of related to that. ...

Age, shift work, and sleep deprivation do affect ability to concentrate effectively, which has a huge adverse effect on older nurses' cognition. While the impacts of ward job demands on the physical and cognitive constructs were widely acknowledged among participants, a similar relationship was less evident with the sensory constructs. For example, participants were resolute that minor visual impairment could be corrected with prescription spectacles; hence, this will normally not affect older nurses' health or work ability in any adverse way. However, an important intersection between the ward job demands and the sensory constructs that was emphasized by the participants is the effect of ward noise levels on hearing. This is a crucial problem in a ward, which is de facto a noisy workplace. Even nurses with mild hearing impairment may struggle to cope cognitively in a noisy ward. So an older nurse with poor hearing might struggle to perform their daily duties on a ward:

... I think that people with hearing problems, they can't manage when, as you say, there's lots of people talking at the same time, which would happen on the ward....

\section{Environmental Demands and the Personal Constructs}

It is appreciated that some of the more modern and purpose-built wards will, to a large extent, support older nurses; however, there seem to be situations whereby the work environment may negatively impact on older nurses' health and well-being. Whichever way, in the interaction between older nurses and the work environment, an adequate level of harmony is necessary, the absence of which poses a huge environmental demand on older nurses. Spatial design is one aspect of the environmental demands that participants claim has an impact on their health. Its most noticeable impact is on the physical constructs, as suggested by a participant:

... I think that on the wards, they're also- they're not particularly well designed, are they? You've got small rooms. So you've got a commode and you've got to get out of this room and through this door, and that's all right when you've got a bit of brute force but I'd say as you get older.... 
Some of the rooms in the wards are too small and it is usually too cumbersome to maneuver in and out of the rooms with patients. Ill-designed work space may, among other things, lead to MSDs, including lower back pains, and strains in the shoulders and neck (Bernal et al., 2015; Heiden et al., 2013). This opinion was buttressed by another participant as follows:

... On our ward, I try to get a patient out of the bed, there is not enough room sometimes to get over the hoisting.... Even the bathrooms, you can't get in with a patient, and shut the door and come out. They are just not designed right....

Environmental demands may also impact on the cognitive constructs, for example, in the form of way-finding. This may in turn reduce productivity at work. In a large healthcare estate with widespread and complex layouts, wayfinding may prove to be a very frustrating exercise for older nurses. Familiarity with the work environment may partially lessen some of the effects of an ill-designed work space layout (Wiles, Leibing, Guberman, Reeve, \& Allen, 2012), however, older nurses with an onset of diminishing cognition may struggle on a daily basis maneuvering through complex healthcare facilities:

There're long corridors that look the same so, sometimes you get a bit disorientated about whether you're on your way to X-ray or Pharmacy.

Even within a relatively small area, nurses cover long distances moving in and around wards. This may be further exacerbated when the activities and work flow are disjointed, resulting in physical monotony and/or fatigue.

So if somebody in Bay One ... wanted a commode and as a younger person you leg it off to get that but as an old person, you cannot move so quickly and then that patient's going to be wondering where the toilet is.

Moving around the ward area is an inescapable part of a nursing job. On the other hand, the performance of tasks in static postures may equally exert latent force on parts of the body causing injury (Baptiste, 2011). Therefore, it is vital that, to the maximum extent possible, nurses' tasks and wards are designed such that the interactions between an older nurse and the work environment do not impair their physical health.

Participants are of the opinion that from a physical constructs perspective, the overall design of the wards is not particularly age friendly, for either older or younger nurses. Participants seem to have an unwavering recognition that younger nurses may be similarly affected by the impacts of these environmental demands:

... There are young nurses complaining. In a nutshell, I wouldn't be able to run the full length of the ward at 68 years old. That could lead to a cardiac arrest really....

Aside from the physical constructs that are being impacted upon by the size and layout of wards, there are other design features that are of concern to participants. There are instances where the design of the ward environment may impact adversely on the sensory constructs. One such feature is the effect of lighting and the balance between natural and artificial sources of light. Participants are apprehensive of the fact that there is no flexibility in allowing natural lights into certain work areas with respect to the needs of patients and employees, so some wards may be blackened out indefinitely:

... The whole unit, the critical care unit has some windows, but they are blackened out ..., so there is no natural light....

It is appreciated that ensuring patient's privacy and dignity in the healing process should be a key priority; however, this must be achieved without compromising the health and well-being of healthcare workers. Older nurses may be at a higher risk of eyestrain due to inadequate ambient lighting, as they are more likely to have sustained some form of visual impairment, however, mild this might be.

Other work environment-related demands like the provision of adequate equipment and tools also have an adverse impact on nurses' health. In particular, the cognitive health of an older 
nurse may be impaired as they may be frustrated by broken or malfunctioning equipment:

... If some of the equipment isn't working, (which) is essential to patient care ..., again with all the bureaucracy, you go through the whole system to get it reported, to get it repaired. It is quite frustrating trying to report fault or anything....

Older nurses frustrated at their job may be at a higher risk of incurring musculoskeletal discomfort (Habibi et al., 2015).

\section{Concluding Discussion}

The first objective of this study was to explore the existing theoretical contexts of the job and environmental demands of the nursing profession. The second objective was to investigate how these jobs and environmental demands impact on the personal constructs of older nurses. Evidence from the literature does suggest that health is a key determinant of older nurses' ability and intention to keep on working. Concomitant to this finding is that the impacts of job and environmental demands on the physical and cognitive constructs have the most severe outcomes for older nurses working in the ward setting.

While the consequences of a highly demanding job on the physical construct may be apparent and, as a result, more likely to be addressed, evidence of diminished cognitive construct may not be easily noticed. The need for the drafting and implementation of measures aimed at redesigning the job and/or the work area to buffer the decline in cognitive acuity may not be readily recognized, hence such help may not be available. Moreover, it is more likely that affected nurses will be able to compensate for pronounced cognitive strain through their experience and familiarity with the work environment. However, this does not fully mitigate the risk of mistakes in patient care.

There is an implicit expectation that older nurses should move on from the ward areas to less demanding roles over time. When such an expectation becomes more vivid, it might easily spill over into noninstitutional work-related negative discrimination. This tacit expectation toward older nurses to exit the ward area earlier may thus pose a potential risk of age discrimination lawsuit against the NHS. This sort of latent ageism may cause mental distress among victimized older nurses and may result in them exiting the job a lot earlier than they may otherwise have done. Even if they do not exit the profession or retire outright, older nurses tend to prepare to leave the ward work area to avoid this psychological pressure. This cause-effect relationship is supported by literature. For instance, many studies have explored the vulnerability of nurses to burnout as a result of challenging job and environmental demands (Adriaenssens, De Gucht, \& Maes, 2015; Duffield et al., 2014; Van Bogaert et al., 2013). Burnout is an important negative predictor of nurses' premature exit from the healthcare sector (Duffield et al., 2014).

The situation on the wards may thus prompt older nurses to want to retire earlier. Those who do stay on the ward may find that promotions are awarded to the younger nurses. So, even if an older nurse stays on the ward, they will most likely be working under the supervision of a younger nurse manager or sister. In the past, when nurses thought they could retire at 55, then they would stay on the ward, but now as they may have to work until their late $60 \mathrm{~s}$, they will move to other positions even before they get to be 55 to gain the expertise needed in their new role as early as possible. Some of the demands of the job may be alleviated through team collaboration. However, due to the nature of ward work, whereby different sets of staff members work in different shifts, the sense of collegiality may be lacking and the chances of getting the support needed for older nurses are reduced.

There is an overwhelming consensus that the participating nurses were satisfied with their jobs. Some participants have been in the practice for more than 10 years. Their commitment to the profession also instigated their desire to ensure the NHS is an age-friendly work environment, as the need for them to work well into their late $60 \mathrm{~s}$ seems to be quite compelling. This reality was a motivating factor in participants' responses. Participants also seem to draw a parallel between the need to support an older nurse and a worker with disability. 


\section{Limitations to Findings}

The limited number of participants and the restricted geographical location of the data collection call for caution in the generalizability of the findings of this study. This research has focused on users of healthcare facilities in the NHS setting (i.e., older nurses); nevertheless, the objective characteristics of the workplace have not been assessed. For example, a comprehensive postoccupancy evaluation of the affected NHS premises may help to gain a more precise knowledge of the nature and the dynamics of the interactions between nurses and their work environment. Furthermore, the tasks older nurses perform on wards were highlighted as described by Dendaas (2011). However, it is necessary to gather further empirical evidence on the nuances of the tasks performed by older nurses in a typical ward setting, to fully appreciate the fit or mismatch between older nurses and their work environment. The main focus of this study is on older nurses, that is, nurses aged 55 years and over; however, the adjustments that may be implemented to the workplace as a result of its findings will equally suit younger nurses, although further research may be necessary in this respect. Findings may also be biased since the participants were volunteers and may have had an interest in the subject matter of the study. A random sample of participants may have yielded different results.

\section{Implications for Practice and Further Research}

The findings of this study may be used as an evidence-based decision-making premise for practice and further research. Identifying challenging job and environmental demands for nurses may serve as a preamble to further research that may seek to create a better fit between nurses' work ability and work environment. There may be a need to introduce job- or task-specific functional capacity for nurses in certain job roles. While it may be necessary to adjust tasks to fit around an older nurse's functional capacity from time to time, this may not always be feasible. Consequently, there may be a need to apply differential treatment in determining the functional capacity of nurses in the context of age. The establishment of a nurse's functional capacity should be monitored to ensure that this is matched with the job and environmental demands, and a well-timed intervention may be facilitated, if necessary. Indices of a scale of a nurse's functional capacity, plotted against measured job demands and environmental demands, will enhance this process.

These findings may also inform design decisions for NHS facilities and therefore preempt the committing of certain design errors that may adversely affect patients' safety and healthcare employees' health, which may be very costly to rectify.

The most compelling finding of this study is that nurses would generally not want to stay on the job if they had to work in the ward area. The five most important job and environmental demands which may lead to the early exit of nurses working in the ward areas are:

- moving and handling of patients,

- fast pace of work,

- risk of committing clinical error,

- lack of collegiality and teamwork, and

- inadequate opportunities for continuous professional development.

Understanding the reasons why older nurses may exit the nursing profession prematurely, especially if they had to work in wards, may help management and policy makers design the ward tasks in order to accommodate the potential health conditions that older nurses may have developed over time.

\section{Acknowledgment}

The authors would like to acknowledge members of staff of Research and Innovation Department Lancashire Teaching Trust, Royal Preston Hospital, and the participants for their support for this study.

\section{Declaration of Conflicting Interests}

The author(s) declared no potential conflicts of interest with respect to the research, authorship, and/or publication of this article. 


\section{Funding}

The author(s) received no financial support for the research, authorship, and/or publication of this article.

\section{References}

Abbas, M. Y., \& Ghazali, R. (2012). Healing environment: Paediatric wards-Status and design trend. Procedia-Social and Behavioral Sciences, 49, 28-38. doi: http://dx.doi.org/10.1016/j.sbspro.2012. 07.003

Adams, A., \& Bond, S. (2000). Hospital nurses' job satisfaction, individual and organizational characteristics. Journal of Advanced Nursing, 32, 536-543. doi:10.1046/j.1365-2648.2000.01513.x

Adriaenssens, J., De Gucht, V., \& Maes, S. (2015). Determinants and prevalence of burnout in emergency nurses: A systematic review of 25 years of research. International Journal of Nursing Studies, 52, 649-661. doi: http://dx.doi.org/10.1016/j.ijnurstu.2014.11.004

Anderson, D. J., \& Webster, C. S. (2001). A systems approach to the reduction of medication error on the hospital ward. Journal of Advanced Nursing, 35, 34-41. doi:10.1046/j.1365-2648.2001.01820.x

Annandale, E., Clark, J., \& Allen, E. (1999). Interprofessional working: An ethnographic case study of emergency health care. Journal of Interprofessional Care, 13, 139-150. doi:10.3109/13561829909025546

Bakker, A. B., \& Demerouti, E. (2007). The job demands-resources model: State of the art. Journal of Managerial Psychology, 22, 309-328.

Bakker, A. B., Demerouti, E., \& Euwema, M. C. (2005). Job resources buffer the impact of job demands on burnout. Journal of Occupational Health Psychology, 10, 170.

Bakker, A. B., Demerouti, E., \& Verbeke, W. (2004). Using the job demands-resources model to predict burnout and performance. Human Resource Management, 43, 83-104.

Bakker, A. B., van Veldhoven, M., \& Xanthopoulou, D. (2010). Beyond the demand-control model: Thriving on high job demands and resources. Journal of Personnel Psychology, 9, 3.

Baptiste, A. (2011). An evaluation of nursing tasks. Work, 40, 115-124.

Barnes, A. F. (2007). Moving and handling. Erasing the word 'lift' from nurses' vocabulary when handling patients. British Journal of Nursing, 16, 1144-1147.

Berger, A. M., \& Hobbs, B. B. (2006). Impact of shift work on the health and safety of nurses and patients. Clinical Journal of Oncology Nursing, 10, 465-471. doi:10.1188/06.cjon.465-471

Bernal, D., Campos-Serna, J., Tobias, A., VargasPrada, S., Benavides, F. G., \& Serra, C. (2015). Work-related psychosocial risk factors and musculoskeletal disorders in hospital nurses and nursing aides: A systematic review and meta-analysis. International Journal of Nursing Studies, 52, 635-648. doi: http://dx.doi.org/10.1016/j.ijnurstu. 2014.11.003

Biggs, S., \& Haapala, I. (2015). Age friendly environments. Journal of Social Work Practice, 29, 1-3. doi:10.1080/02650533.2014.993941

Bircher, J. (2005). Towards a dynamic definition of health and disease. Medicine, Health Care and Philosophy, 8, 335-341. doi:10.1007/s11019-005-0538-y

Bourbonnais, R., Comeau, M., Vézina, M., \& Dion, G. (1998). Job strain, psychological distress, and burnout in nurses. American Journal of Industrial Medicine, 34, 20-28. doi:10.1002/(sici)10970274(199807)34:1<20:: aid-ajim4>3.0.co;2-u

Carlson, E., Rämgård, M., Bolmsjö, I., \& Bengtsson, M. (2014). Registered nurses' perceptions of their professional work in nursing homes and homebased care: A focus group study. International Journal of Nursing Studies, 51, 761-767. doi: http://dx.doi.org/10.1016/j.ijnurstu.2013.10.002

Coetzee, S. K., \& Klopper, H. C. (2010). Compassion fatigue within nursing practice: A concept analysis. Nursing \& Health Sciences, 12, 235-243. doi:10. 1111/j.1442-2018.2010.00526.x

Cope, V., Jones, B., \& Hendricks, J. (2014). Why nurses chose to remain in the workforce: Portraits of resilience. Collegian. doi: http://dx.doi.org/10. 1016/j.colegn.2014.12.001

Cousins, D. H., Gerrett, D., \& Warner, B. (2012). A review of medication incidents reported to the National Reporting and Learning System in England and Wales over 6 years (2005-2010). British Journal of Clinical Pharmacology, 74, 597-604. doi:10.1111/j.1365-2125.2011.04166.x

Deacon, M., \& Cleary, M. (2013). The reality of teamwork in an acute mental health ward. Perspectives in Psychiatric Care, 49, 50-57. doi: 10.1111/j.1744-6163.2012.00340.x 
De Jonge, J., \& Dormann, C. (2006). Stressors, resources, and strain at work: A longitudinal test of the triple-match principle. Journal of Applied Psychology, 91, 1359.

Demerouti, E., \& Bakker, A. B. (2011). The job demands-resources model: Challenges for future research. SA Journal of Industrial Psychology, 37, $1-9$.

Dendaas, N. (2011). Environmental congruence and work-related stress in acute care hospital medical/ surgical units: A descriptive, correlational study. Health Environments Research \& Design Journal, 5, 23-42.

Djukic, M., Kovner, C., Budin, W. C., \& Norman, R. (2010). Physical work environment: Testing an expanded model of job satisfaction in a sample of registered nurses. Nursing Research, 59, 441-451. doi:10.1097/NNR.0b013e3181fb2f25

Dollard, M. F., Winefield, H. R., Winefield, A. H., \& Jonge, J. (2000). Psychosocial job strain and productivity in human service workers: A test of the demand-control-support model. Journal of Occupational and Organizational Psychology, 73, 501-510.

Douglas, C. H., \& Douglas, M. R. (2005). Patientcentred improvements in health-care built environments: Perspectives and design indicators. Health Expectations, 8, 264-276. doi:10.1111/j.13697625.2005.00336.x

Drey, N., Gould, D., \& Allan, T. (2009). The relationship between continuing professional education and commitment to nursing. Nurse Education Today, 29, 740-745. doi: http://dx.doi.org/10.1016/j.nedt. 2009.03.008

Duffield, C., Graham, E., Donoghue, J., Griffiths, R., Bichel-Findlay, J., \& Dimitrelis, S. (2014). Why older nurses leave the workforce and the implications of them staying. Journal of Clinical Nursing. doi:10.1111/jocn.12747

Fitzgerald, D. C. (2007). Aging, experienced nurses: Their value and needs. Contemporary Nurse: $A$ Journal for the Australian Nursing Profession, 24, 237-243. doi:10.5172/conu.2007.24.2.237

Freeman, T. (2006). 'Best practice' in focus group research: Making sense of different views. Journal of Advanced Nursing, 56, 491-497. doi:10.1111/j. 1365-2648.2006.04043.x

Frijters, P., Shields, M. A., \& Price, S. W. (2007). Investigating the quitting decision of nurses: Panel data evidence from the british national health service. Health Economics, 16, 57-73. doi:10.1002/ hec. 1144

Gevers, J., Van Erven, P., De Jonge, J., Maas, M., \& De Jong, J. (2010). Effect of acute and chronic job demands on effective individual teamwork behaviour in medical emergencies. Journal of Advanced Nursing, 66, 1573-1583. doi:10.1111/j.1365-2648. 2010.05314.x

Gould, D., Drey, N., \& Berridge, E.-J. (2007). Nurses' experiences of continuing professional development. Nurse Education Today, 27, 602-609. doi: http://dx.doi.org/10.1016/j.nedt.2006.08.021

Gross, M. D. R., Sasson, M. D. Y., Zarhy Architect, M., \& Zohar, M. D. J. (1998). Healing environment in psychiatric hospital design. General Hospital Psychiatry, 20, 108-114. doi: http://dx.doi.org/10. 1016/S0163-8343(98)00007-3

Habibi, E., Taheri, M. R., \& Hasanzadeh, A. (2015). Relationship between mental workload and musculoskeletal disorders among Alzahra Hospital nurses. Iranian Journal of Nursing \& Midwifery Research, 20, 1-6.

Haight, J. M., \& Belwal, U. (2006). Designing for an aging workforce (Cover story). Professional Safety, 51, 20-33.

Hall, G. B., Dollard, M. F., Winefield, A. H., Dormann, C., \& Bakker, A. B. (2013). Psychosocial safety climate buffers effects of job demands on depression and positive organizational behaviors. Anxiety, Stress \& Coping, 26, 355-377. doi:10.1080/10615806. 2012.700477

Han, K., Trinkoff, A. M., \& Geiger-Brown, J. (2014). Factors associated with work-related fatigue and recovery in hospital nurses working 12-hour shifts. Workplace Health \& Safety, 62, 409-414. doi:10. 1097/NNA.0b013e3181d0414e, http://dx.doi.org/ 10.3928/21650799-20140826-01

Harris, R., Bennett, J., Davey, B., \& Ross, F. (2010). Flexible working and the contribution of nurses in mid-life to the workforce: A qualitative study. International Journal of Nursing Studies, 47, 418-426. doi: http://dx.doi.org/10.1016/j.ijnurstu. 2009.08.009

Health and Social Care Information Centre. (2015). Workforce [standard]. doi: http://www.hscic.gov. uk/workforce

Heiden, B., Weigl, M., Angerer, P., \& Müller, A. (2013). Association of age and physical job 
demands with musculoskeletal disorders in nurses. Applied Ergonomics, 44, 652-658. doi: http://dx. doi.org/10.1016/j.apergo.2013.01.001

Hignett, S., \& Evans, D. (2006). Spatial requirements in hospital shower and toilet rooms. Nursing Standard, 21, 43-48.

Hinno, S., Partanen, P., \& Vehviläinen-Julkunen, K. (2011). Hospital nurses' work environment, quality of care provided and career plans. International Nursing Review, 58, 255-262. doi:10.1111/j.14667657.2010.00851.x

Hobfoll, S. E. (1989). Conservation of resources: A new attempt at conceptualizing stress. American Psychologist, 44, 513.

Hobfoll, S. E. (2002). Social and psychological resources and adaptation. Review of General Psychology, 6, 307.

Hollingdale, R. (1997). Back pain in nursing and associated factors: A study. Nursing Standard, 11, 35-38. doi:10.7748/ns1997.06.11.39.35.c2460

Holman, G. T., Ellison, K. J., Maghsoodloo, S., \& Thomas, R. E. (2010). Nurses' perceptions of how job environment and culture influence patient handling. International Journal of Orthopaedic and Trauma Nursing, 14, 18-29. doi: http://dx.doi.org/10.1016/ j.joon.2009.03.004

HSE. (1992). The manual handling operations regulations 1992 (as amended). Retrieved September 1, 2015, from http://www.hse.gov.uk/foi/internalops/ ocs/300-399/313_5.htm

Huisman, E. R. C. M., Morales, E., van Hoof, J., \& Kort, H. S. M. (2012). Healing environment: A review of the impact of physical environmental factors on users. Building and Environment, 58, 70-80. doi: http://dx.doi.org/10.1016/j.buildenv.2012.06. 016

Jarvis, P. (2005). Lifelong education and its relevance to nursing. Nurse Education Today, 25, 655-660. doi: http://dx.doi.org/10.1016/j.nedt.2005.09.005

Jones, S. W. (2009). Reducing medication administration errors in nursing practice. Nursing Standard, 23,40 .

Jourdain, G., \& Chênevert, D. (2010). Job demandsresources, burnout and intention to leave the nursing profession: A questionnaire survey. International Journal of Nursing Studies, 47, 709-722. doi: http://dx.doi.org/10.1016/j.ijnurstu.2009.11.007

Kaplowitz, M. D., \& Hoehn, J. P. (2001). Do focus groups and individual interviews reveal the same information for natural resource valuation? Ecological Economics, 36, 237-247. doi: http://dx.doi. org/10.1016/S0921-8009(00)00226-3

Karasek, R. A. (1979). Job demands, job decision latitude, and mental strain: Implications for job redesign. Administrative Science Quarterly, 24, 285-308.

Kirwan, M., Matthews, A., \& Scott, P. A. (2013). The impact of the work environment of nurses on patient safety outcomes: A multi-level modelling approach. International Journal of Nursing Studies, 50, 253-263. doi: http://dx.doi.org/10.1016/j.ijnurstu. 2012.08.020

Krueger, R. A., \& Casey, M. A. (2009). Focus groups: A practical guide for applied research (4th ed.). Thousand Oaks, CA: Sage.

Lamontagne, I., Levesque, B., Gingras, S., Maurice, P., \& Verreault, R. (2004). Environmental hazards for falls in elders in low income housing. Revue $D$ Epidemiologie Et De Sante Publique, 52, 19-27. doi:10.1016/s0398-7620(04)99019-0

Lara, J., Godfrey, A., Evans, E., Heaven, B., Brown, L. J. E., Barron, E., . . Mathers, J. C. (2013). Towards measurement of the Healthy Ageing Phenotype in lifestyle-based intervention studies. Maturitas, 76, 189-199. Retrieved from http://dx.doi.org/10. 1016/j.maturitas.2013.07.007

Lavoie-Tremblay, M., Trépanier, S.-G., Fernet, C., \& Bonneville-Roussy, A. (2014). Testing and extending the triple match principle in the nursing profession: A generational perspective on job demands, job resources and strain at work. Journal of Advanced Nursing, 70, 310-322. doi:10.1111/ jan. 12188

Lawton, M. P., \& Nahemow, L. (1973). Toward an ecological theory of adaptation and aging 1.3. Environmental Design Research: Selected papers, 1, 24.

legislation.gov.uk. (2013). Data protection act 1998. Statute Law Database. Retrieved from http://www. legislation.gov.uk/ukpga/1998/29/contents

Letvak, S. (2005). Health and safety of older nurses. Nursing Outlook, 53, 66-72. doi: http://dx.doi.org/ 10.1016/j.outlook.2004.09.005

Lewin, K. (1951). Field theory in social science: Selected theoretical papers (D. Cartwright, Ed.). Oxford, England: Harpers.

Liu, W., Manias, E., \& Gerdtz, M. (2014). The effects of physical environments in medical wards on medication communication processes affecting patient 
safety. Health \& Place, 26, 188-198. Retrieved from http://dx.doi.org/10.1016/j.healthplace.2013.12.017

Mark, B. A., Hughes, L. C., Belyea, M., Chang, Y., Hofmann, D., Jones, C. B., \& Bacon, C. T. (2007). Does safety climate moderate the influence of staffing adequacy and work conditions on nurse injuries? Journal of Safety Research, 38, 431-446. Retrieved from http://dx.doi.org/10. 1016/j.jsr.2007.04.004

Marshall, N. L., Barnett, R. C., \& Sayer, A. (1997). The changing workforce, job stress, and psychological distress. Journal of Occupational Health Psychology, 2, 99-107.

McLafferty, I. (2004). Focus group interviews as a data collecting strategy. Journal of Advanced Nursing, 48, 187-194. doi:10.1111/j.1365-2648.2004.03186.x

McNeely, E. (2005). The consequences of job stress for nurses' health: Time for a check-up. Nursing Outlook, 53, 291-299. Retrieved from http://dx.doi. org/10.1016/j.outlook.2005.10.001

Meijman, T. F., \& Mulder, G. (1998). Psychological aspects of workload. In P. J. D. Drenth \& H. Thierry (Eds.), Handbook of work and organizational psychology (Vol. 2, pp. 5-33). Hove, England: Psychology Press.

Morrison, K. B., \& Korol, S. A. (2014). Nurses' perceived and actual caregiving roles: Identifying factors that can contribute to job satisfaction. Journal of Clinical Nursing, 23, 3468-3477. doi:10.1111/ jocn. 12597

Mourshed, M., \& Zhao, Y. (2012). Healthcare providers' perception of design factors related to physical environments in hospitals. Journal of Environmental Psychology, 32, 362-370. Retrieved from http://dx.doi.org/10.1016/j.jenvp.2012.06.004

Nelsey, L., \& Brownie, S. (2012). Effective leadership, teamwork and mentoring-Essential elements in promoting generational cohesion in the nursing workforce and retaining nurses. Collegian, 19, 197-202. Retrieved from http://dx.doi.org/10.1016/ j.colegn.2012.03.002

NHS Business Services Authority. (2015). NHS Pension Scheme: Arrangements beyond 1 April 2015. Retrieved August 31, 2015, from http://www. nhsbsa.nhs.uk/Pensions/4017.aspx

NHS LTHTR. (2015). Elderly medicine-Lancashire teaching hospitals. Retrieved April 16, 2015, from http://www.lancsteachinghospitals.nhs.uk/elderlymedicine
Nolan, M., Grant, G., Brown, J., \& Nolan, J. (1998). Assessing nurses' work environment: Old dilemmas, new solutions. Clinical Effectiveness in Nursing, 2, 145-154. Retrieved from http://dx.doi.org/ 10.1016/S1361-9004(98)80011-3

O'Shea, E. (1999). Factors contributing to medication errors: A literature review. Journal of Clinical Nursing, 8, 496-504. doi:10.1046/j.1365-2702.1999. 00284. $\mathrm{x}$

Page, A. (2004). Keeping patients safe: Transforming the work environment of nurses. Washington, DC: National Academies Press.

Pisarski, A., \& Barbour, J. P. (2014). What roles do team climate, roster control, and work life conflict play in shiftworkers' fatigue longitudinally? Applied Ergonomics, 45, 773-779. Retrieved from http://dx.doi.org/10.1016/j.apergo.2013.10.010

Pool, I., Poell, R., \& ten Cate, T. J. (2013). Perspectives on age and continuing professional development for nurses: A literature review. Vocations and Learning, 6, 297-321. doi:10.1007/s12186-013-9096-2

Quoidbach, J., \& Hansenne, M. (2009). The impact of trait emotional intelligence on nursing team performance and cohesiveness. Journal of Professional Nursing, 25, 23-29. Retrieved from http://dx.doi. org/10.1016/j.profnurs.2007.12.002

Roelen, C., van Rhenen, W., Schaufeli, W., van der Klink, J., Magerøy, N., Moen, B., ... Pallesen, S. (2014). Mental and physical health-related functioning mediates between psychological job demands and sickness absence among nurses. Journal of Advanced Nursing, 70, 1780-1792. doi:10.1111/ jan. 12335

Royal College of Nursing. (2012). A shift in the right direction: Royal College of Nursing guidance. Retrieved August 31, 2015, from http://rcn.funnelback.co.uk/search/search.cgi?query $=$ average + shift + hour + per + nurse \& collection $=$ rcn-meta\&section $=$ $\&$ profile $=\_$default

Sharma, A., Sharp, D. M., Walker, L. G., \& Monson, J. R. T. (2008). Stress and burnout among colorectal surgeons and colorectal nurse specialists working in the National Health Service. Colorectal Disease, 10, 397-406. doi:10.1111/j.1463-1318. 2007.01338.x

Shields, M. A., \& Ward, M. (2001). Improving nurse retention in the National Health Service in England: The impact of job satisfaction on intentions to quit. Journal of Health Economics, 
20, 677-701. Retrieved from http://dx.doi.org/10. 1016/S0167-6296(01)00092-3

Smedley, J., Inskip, H., Trevelyan, F., Buckle, P., Cooper, C., \& Coggon, D. (2003). Risk factors for incident neck and shoulder pain in hospital nurses. Occupational and Environmental Medicine, 60, 864-869.

Soer, R., Hollak, N., Deijs, M., van der Woude, L. H., \& Reneman, M. F. (2014). Matching physical work demands with functional capacity in healthy workers: Can it be more efficient? Applied Ergonomics, 45, 1116-1122. Retrieved from http://dx.doi.org/ 10.1016/j.apergo.2014.01.011

Unruh, L., \& Zhang, N. J. (2013). The role of work environment in keeping newly licensed RNs in nursing: A questionnaire survey. International Journal of Nursing Studies, 50, 1678-1688. Retrieved from http://dx.doi.org/10.1016/j.ijnurstu.2013.04.002

Van Bogaert, P., Kowalski, C., Weeks, S. M., Van heusden, D., \& Clarke, S. P. (2013). The relationship between nurse practice environment, nurse work characteristics, burnout and job outcome and quality of nursing care: A cross-sectional survey. International Journal of Nursing Studies, 50, 1667-1677. Retrieved from http://dx.doi.org/10. 1016/j.ijnurstu.2013.05.010

Van den Broeck, A., De Cuyper, N., De Witte, H., \& Vansteenkiste, M. (2010). Not all job demands are equal: Differentiating job hindrances and job challenges in the Job Demands-Resources model. European Journal of Work and Organizational Psychology, 19, 735-759. doi:10.1080/13594320 903223839

Van Den Tooren, M., \& De Jonge, J. (2008). Managing job stress in nursing: What kind of resources do we need? Journal of Advanced Nursing, 63, 75-84.

Van Yperen, N. W., \& Hagedoorn, M. (2003). Do high job demands increase intrinsic motivation or fatigue or both? The role of job control and job social support. Academy of Management Journal, 46, 339-348. doi:10.2307/30040627

Verhaeghe, R., Vlerick, P., De Backer, G., Van Maele, G., \& Gemmel, P. (2008). Recurrent changes in the work environment, job resources and distress among nurses: A comparative cross-sectional survey. International Journal of Nursing Studies, 45, 382-392. Retrieved from http://dx.doi.org/10.1016/ j.ijnurstu.2006.10.003

Wang, S. M., Lai, C. Y., Chang, Y.-Y., Huang, C.Y., Zauszniewski, J. A., \& Yu, C.-Y. (2015). The relationships among work stress, resourcefulness, and depression level in psychiatric nurses. Archives of Psychiatric Nursing, 29, 64-70. Retrieved from http://dx.doi.org/10.1016/j.apnu. 2014.10.002

Wiles, J. L., Leibing, A., Guberman, N., Reeve, J., \& Allen, R. E. S. (2012). The meaning of "Aging in place" to older people. Gerontologist, 52, 357-366.

Wilson, C. B. (2001). Safer handling practice for nurses: A review of the literature. British Journal of Nursing, 10, 108-114.

World Health Organization. (1948). Definition of health. WHO Constitution. Retrieved April 16, 2015, from http://www.who.int/about/en/

Wray, J., Aspland, J., Gibson, H., Stimpson, A., \& Watson, R. (2009). "A wealth of knowledge": A survey of the employment experiences of older nurses and midwives in the NHS. International Journal of Nursing Studies, 46, 977-985. Retrieved from http://dx.doi.org/10.1016/j.jinurstu.2008.07. 008

Wright, K. (2014). Alleviating stress in the workplace: advice for nurses. Nursing Standard, 28, 37-42.

www.gov.uk. (2015). Retirement age. Retrieved August 31, 2015, from https://http://www.gov.uk/ retirement-age

Yaffe, K., Falvey, C. M., \& Hoang, T. (2014). Connections between sleep and cognition in older adults. The Lancet Neurology, 13, 1017-1028. Retrieved from http://dx.doi.org/10.1016/S14744422(14)70172-3

Zito, M., Cortese, C. G., \& Colombo, L. (2015). Nurses' exhaustion: The role of flow at work between job demands and job resources. Journal of Nursing Management. doi:10.1111/jonm.12284 